\title{
Robotics: Enhancing Pre-College Mathematics Learning with Real-world Examples
}

\section{Dr. Ravi T. Shankar, Florida Atlantic University}

Dr. Ravi Shankar is a professor in the computer and electrical engineering and computer science (CEECS) department in the college of engineering and computer science (COECS) at Florida Atlantic University (FAU) at Boca Raton, Fla. He is the director of a college-wide center on systems integration. He has a Ph.D. from the University of Wisconsin, Madison, Wisc., and an M.B.A. from FAU. He is a registered Professional Engineer in the State of FL, a Senior member of IEEE, and a fellow of the American Heart Association.

\section{Dr. Don Ploger, Florida Atlantic University}

Dr. Don Ploger, Ph.D., is an Associate Professor with the College of Education. He and Dr. Shankar have worked together in developing Robotics courses for high school students. Dr. Ploger brings two important perspectives to this collaborative research. First, from an engineering education perspective, he emphasizes the importance of communicating essential knowledge to non-engineers. The second perspective comes from the mathematics education research literature. There is a well-established paradox: students often fail to apply familiar methods when they attempt to solve novel problems. Coordinating these perspectives has facilitated the collaboration across disciplines.

\section{Ms. Agnes Nemeth, Florida Atlantic University \\ Dr. Steven Alan Hecht Ph.D., Nova Southeastern University}




\section{Robotics: Enhancing Pre-College Mathematics Learning with Real-world Examples}

\section{Abstract:}

Seventeen ninth grade students worked in teams to build their own low cost robots, program them and use them to draw various geometric shapes. The course was designed to enhance their interest in engineering and math, while providing a social context of empowerment, competition and cooperation. This paper will document our past and planned efforts to integrate robotics into high school math curriculum. Our goal is to build low-cost robots that can be purchased or built incrementally to manage budgetary restrictions. These robots should be reliable, robust, and most important of all, be customizable for the specific needs of the teacher and the student teams. Furthermore, we integrated the robots into math lessons.

The results indicate that students in our robotics program benefited from the use of robots. We looked at a problem that students solved using the Pythagorean Theorem and then analyzed the results of the robotic simulation. The students correctly interpreted both the mathematical problem and the real world error that was produced when using the robots. Students were also able to understand the difference between conceptual error and real world error. The students recognized that the robots they built could be used as an instructional tool to a wider range of audience. In all, these clinical interviews explicitly show how students used the robotic art approach to better conceptualize and solve math problems.

We also examined the two-boat problem that we intend to use in our future robotics math classroom. The problem is visually and dynamically solved. Successive approximation is used to identify a trend and come close to a solution. Using robots, students can guess and check to make sense of the problem then look at it from different angles and solve it in many ways. Students need to explore different estimates and evaluate each one until they come close to the solution. After examining the problem from so many different perspectives, they are now comfortable that the result they have gotten with the robots is near to the mathematically correct solution. Students can stop with the robotic investigation at any point and solve the problem algebraically.

Learning mathematics with robots helps students visualize challenging real world applications and supports multiple representations of a problem. While students apply their knowledge of math concepts solving real world problems with the help of robots, they develop a lasting handson experience in a social context and a better attitude towards math education. Building low cost robots that schools can afford would ensure access, availability and foster mainstream instruction with robots that would help prepare our next generation in math and engineering principles.

\section{Introduction:}

II. A. Overview: Seventeen ninth grade students worked in teams to build their own low cost robots, program them, and use them to draw various geometric shapes on a canvas of 6' x 6', all during a regular semester long course. The course was designed to enhance their interest in engineering and math, while providing a social context of empowerment, competition and cooperation. This paper will document our past and planned efforts to integrate robotics into high school math curriculum. We are driven by two fundamental objectives: (1) Build low cost 
robots that can be purchased or built incrementally to manage budgetary restrictions. These robots should be re liable, robust, and most important of all, be customizable for the specific needs of the teacher and the student teams; and (2) adapt the approach of "Understanding by Design" by Wiggins and McTighe ${ }^{1}$ in integrating robots into math lessons. They recommend a three-stage process: define objectives; determine assessments, and develop tasks (in our case, robotics based exercises).

For the first objective, we will provide details of our on-going work on building low cost robots that every K-12 school can afford. It is based on open source principles, making it easy to learn from the robotic community, and to innovate and contribute back to the community. In this paper, we will describe how students in this robotics program benefited from the use of robots. An interview and a problem solving sequence will be shortly illustrated. New ideas and lessons will evolve that can provide a small remuneration to the inventors, while as a larger community we will all make progress in educating our next generation in math and engineering principles. There is also potential for many exciting extensions.

For the second objective, we have used "Algebra 2: Common Core" by Charles et al., ${ }^{2}$ as the starting point to seek this mapping. This book fully aligns with the Common Core State Standards ${ }^{3}$. Further, Dr. Wiggins is a co-author of this book, thus ensuring that this book is faithful to the Understanding by Design (UbD) philosophy ${ }^{1}$.

As a continuum and extension to our existing robotics initiatives, we have planned a future program that will utilize robots in the mathematics classroom. In our paper, we will show some of the possible uses of robots in improving math understanding.

We have made available all our course assets (robot design, Apps, code, and presentation videos) at a university website ${ }^{4}$. We visualize this as a community resource that other researchers and educators can leverage to improve and adopt; we hope they will share their lessons and tools with the larger community. We also seek the feedback of the reader to improve our approach.

II.B. Literature and Product Review: Although there is a clear lack of quantitative research on how robots can increase STEM achievement in students, and some of the research findings are inconclusive $\mathrm{e}^{5}$, most of the studies have shown positive correlation between the use of robots and students motivation towards STEM careers. Robotics is recognized by NSF to be an excellent vehicle for education and involving students in science and engineering, and, with the proper initiative, motivate promising students to pursue career tracks in mathematics and its applications $^{6}$.

Robots also promote learning of scientific and mathematic principles through experimentation ${ }^{7}$. Bringing robots into the classrooms will have lasting benefits. When students learn with robots they will inevitably learn about many other disciplines ${ }^{7,8}$. Students will learn to apply knowledge of math in novel ways to real world problems developing a richer knowledge base for their math education ${ }^{9}$.

To teach mathematics with robots requires lessons that focus, motivate and highlight the mathematics in a meaningful way. Just because the math is present in an activity, it doesn't 
indicate that students will learn math. The instruction, robots and lessons have to be carefully designed in an integrated manner to achieve that goal. Unit activities have to be so tightly interwoven with an important math concept that the students couldn't help but learn about the math in order to solve the design problem ${ }^{10}$.

The popular Logo environment has involved the Turtle, originally a robotic creature that moved around on the floor ${ }^{11}$. Logo can be a very powerful tool to help children - and college students learn mathematics. It could help kindergarten children write simple programs to draw interesting shapes. It has also been used by college students to solve difficult problems in calculus.

Despite its many potential benefits, Logo did not become part of the school math curriculum, and it is not referenced in the Core Curriculum Standards. It is, however, possible to create something that has many of the good points of Logo, and still connect it to classroom practice.

Other academic robotic platforms such as Lego ${ }^{13}$ and $\mathrm{VEX}^{14}$ are expensive (\$265 to \$350), and for some schools, cost is the difference between robots and no robots. In comparison, our starter robot will cost $\$ 100$. While Lego and VEX are proprietary, we use the open source tools of Arduino and extend it to robotics. There is a need for an open source approach to help all to learn from each other and increase the number of lessons and examples. Lego is too sophisticated; using them might set students' expectations too high at present but might hinder them while solving engineering problems in an optimal manner when they move to college or a job. This complexity may also discourage some students from under-represented communities from entering the STEM fields.

CMU's Robotics Academy is working to provide research-based documentation for educators interested in teaching 21 st century skill sets to children ${ }^{12}$. Their belief is that when you have students "doing" as opposed to watching, they will be able to build concrete bonds to the concepts they are learning. These bonds will enable new learners to reconstruct and synthesize the information later, which in turn will lead to deeper understanding. The links at their site provide access to papers and research that others have posted on the web. This list is by no means comprehensive and the Robotics Academy does not agree or disagree with all of the findings of the authors of these papers. These papers serve as food for thought for anyone using or considering using robotics and alternative assessment strategies in their classroom ${ }^{5,6}$.

II.C. Background: The journey towards our previous projects started when we came to know that a local school had a robotics club, but no robots. The students, both boys and girls, met once a week to discuss, but could make no headway on how to finance their club. Purchase, operation, and maintenance of commercially available robots ${ }^{13,14}$ were beyond their means and capability. We wanted a simple low cost solution that they could easily comprehend and build upon. To this end, we offered a course to engineering undergraduate students in the fall of 2011. The result was a blueprint (for both hardware and software) for building a low cost robot ${ }^{4}$. We have published the details elsewhere ${ }^{15}$. The technical details are available online at our website ${ }^{16}$.

We also wanted the robot to fit into the K-12 science, technology, engineering, and mathematics (STEM) curriculum, specifically in math and science, so more students would benefit from it, rather than a small group who is motivated to participate in a robotics club. Studies in the 
mathematics education research indicate that students may be able to recall certain facts, but fail to use those facts in solving novel problems. Some students do not even recognize that solving such problems is important. Students often "give clear evidence of knowing certain mathematics but then proceed to act as if they are completely ignorant of it" ${ }^{17}$. Bringing engineering technology into the mathematics classroom can help students understand the subject matter more deeply than in traditional mathematics instruction. We need to help expand our students' mathematical toolbox: they need to learn the rules, concepts and formulas to solve mathematical problems. Students who only encounter the abstract nature of mathematics often describe it as a boring and dry subject and state that they never learn anything that they could use in real life. When practicum and pure thought are inextricably intertwined, that is real math instruction. Teaching math with robots combines these two sides of mathematics. This is detailed in another paper by us ${ }^{18}$.

There is a rich literature on the use of robots, computers and simulation tools to further the K-12 education. As a girl in 11th grade at another local school commented recently, "We had a robotics class where we assembled and pushed buttons; but we really did not learn anything." We provide here a different approach, of having students as partners, rather than mere users, in designing and developing their lessons. Hands-on team based activities and consequent social networking will also help them channel their energies better, reinforce each other's learning, and collaboratively achieve more elegant solutions.

II.D. Possible Extension to the Robotics Program: To achieve semester end goals, students in

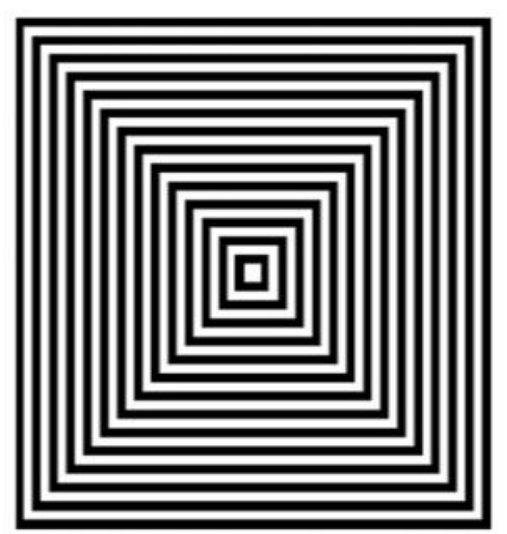
the robotics program first learned, as a class, to program their robots to draw lines, circles and simple polygons, in various shapes and sizes, and with nesting. These components were then used as building blocks to create simple robotic art that they presented at semester end. Such art, after a few course offerings, may mature enough to be construed as creating something that is visual and inherently interesting to viewers, in the sense that the robots can be used to create a visual representation of geometric patterns; this can be highly motivating to students. STEM with Arts (STEAM/ TEAMS) has recently gained momentum ${ }^{19,20}$. See Figure 1 for an example of a potential future robotic art project for this course ${ }^{21}$.

Figure 1: Concentric Squares

We also want to develop ways to sustain a larger community while facilitating individual schools to achieve sustenance with their own innovation and creativity. For this to happen, one needs to note that this robotic infrastructure also furthers the goals of STEM, since a robotic platform would require seamless integration of all the STEM disciplines. For this reason, we have focused mainly on open source and component technologies for both hardware and software, so one could mix and match components that achieve the same end goal, perhaps with variation in one of the many system metrics, such as cost, speed, battery life, ease of use, etc. Challenges, however, abound. Sophisticated robotics as practiced elsewhere ${ }^{22}$ require advanced knowledge, skill-set, and access to expensive hardware and software. The developers of Arduino have already addressed these issues by providing an user-friendly (higher level) interface and an open 
source tool suite ${ }^{23}$, to primarily aid artists in developing physical computing applications ${ }^{24}$. The open source platform uses a state-of-the-art microcontroller from ATMEL ${ }^{25}$. Further, we want to build a central resource that provides the most current information on our robotics platform, as Arduino has done for their embedded system platform. We have made progress in that direction with our current university website ${ }^{4}$ on robotics. We hope others around the world will access the information and benefit from it and to contribute to it, to further reduce the cost and the barrier to learning and innovation. We also have followed a similar path in developing our capabilities in building smart phone Apps. The associated website ${ }^{26}$ has had over $200 \mathrm{~K}$ visits from developers around the world in the past 30 months.

In developing this flow, we have benefitted enormously from a six year industry grant on significantly improving a systems company's engineering design productivity ${ }^{27,} 28$. We were immensely helped by the open source software and hardware from Arduino ${ }^{23}$, as mentioned above; it allows one to use low cost off-the-shelf components to assemble and program rapidly a microcontroller-based system. We extended this to build robots. The robot software and hardware were prototyped a priori by engineering college students ${ }^{29,18}$, so we knew that the flow for high school students would be predictable and repeatable, and that robots built would be robust.

We were able to develop this infrastructure during multiple semesters, thanks to supportive administrators at our engineering college and the high school who saw value in supporting such explorations. They are once again behind our efforts as we attempt to put this platform in the right context to find ways to use it to benefit math education.

\section{Relevance:}

III.A. Mapping Robot Use to the Common Core Standards: A famous story says that the initial flash of analytic geometry came to Descartes by watching the fly crawling about on the ceiling near a corner of his room. It struck him that the path of the fly on the ceiling could be described if only one knew the relation connecting the fly's distances from two adjacent walls. Even though this story may be apocryphal, it has good pedagogic value ${ }^{30,31}$.

The content of the math curricula has been fairly constant (Algebra is still Algebra), however, the way we teach math, our aim, the educational methodologies and strategies we use must be adjusted to meet the needs of our 21 st century students. These students have fundamentally different goals, interest and motivation. Today's learners recognize that going to school is not about earning a certificate but learning valuable and marketable knowledge and skills that can be utilized in their future professions. The high school diploma is far from a final destination; it is only a tool. The practice, training and professional development they gain during their school years must count as significant for the world of work. Teachers have to keep in mind that their students are affected by technology gadgets, the information and media revolution, as well as by economic and social changes. Educators need to develop and deliver instructions that are relevant to the students.

Mathematics is dualistic: it is pure science as it is the achievements of human thought; a timeless, yet ever-evolving system. On the other hand, mathematics is a tool; it offers real life 
applications and practical usefulness in solving real life problems. The effectiveness of the teachers' work can be determined by finding the correct proportions in this duality.

Teachers' ultimate goal is to prepare students for the future and to teach them the necessary skills to become well rounded individuals who are valuable assets to the workforce, to our global economy and to our society. The mission of teachers therefore is to implant their expertise into their students regardless of the subject they teach. If a student pursues a math related profession, math proficiency is absolutely necessary. However, math skills are essential and will benefit students regardless of the career path they take. Bare math skills that involve numbers, variables and operations only (as math taught today in most of the classroom), however, are insufficient for career preparedness.

The Common Core Standards were developed in collaboration with teachers, school administrators, and experts, to provide a clear and consistent framework to prepare our children for college and the workforce ${ }^{3}$.

The Mission Statement declares that the "Common Core State Standards provide a consistent, clear understanding of what students are expected to learn, so teachers and parents know what they need to do to help them. The standards are designed to be robust and relevant to the real world, reflecting the knowledge and skills that our young people need for success in college and careers. With American students fully prepared for the future, our communities will be best positioned to compete successfully in the global economy." 32

In contrast to the Common Core Initiative's Mission, our students like straightforward math assignments. Most of them would be able to solve problems that are in the forms of mathematical expressions or equations. When students encounter a problem of the sort (simplify the expressions or solve for $\mathrm{x}$ for example) they would have no or minimal difficulty. If, however, the same mathematical expressions or equations are hidden in a context, many students do not know how to start solving that problem.

This aversion towards word problems and real world applications is not new; students have always struggled with them. Even high achieving students who have mastered the math skills that lay behind a real life application problem would admit their difficulty and even dislike toward word problems. Some would even come to a standstill or simply give up when encountered a more involving, multi-step problem where the math skill that needed to solve the problem is not instantly obvious.

III.B. Graphing Calculators and Robots in the Math Classrooms: In a peer reviewed research done by Ellington in 2003, the benefits of using graphing calculators were analyzed. The meta-analysis of 54 high-quality studies, 22 specifically on graphing calculators, were to determine the effects of calculator use on students' performance in five skill areas: conceptual, computational, operational, problem solving and selectivity. Survey data was also collected on students' attitudes toward mathematics and related to calculator usage. The results of that study clearly stated the benefits of graphing calculator use. Students who received instruction using graphing calculators performed as well or significantly better in conceptual, problem solving and operational skill areas. Students using calculators during instruction - but not during assessment 
- performed as well or better in all five math skill areas. Students using calculators had better attitudes toward mathematics than students who did not use calculators ${ }^{33}$.

III.C. Robots versus Graphing Calculators: Although the graphing calculator is a great learning tool to help students solve even the most complicated math problems, it has its inadequacies. Among other disadvantages, a graphing calculator is designed for individual use and using them is not considered a hands-on activity.

Robots, on the other hand, not only help students visualize and better understand concepts in math and science but require team work in a "get down to your knees and work with your hands" way. Robots support multiple representations of a problem that is shown to increase students' use of visualization in problem solving and gains in understanding. This visualization is an important part of solving real life math problems; it allows students to make real-world connections in a variety of subjects. As they gain a deeper understanding of the material, they will acquire the critical thinking and problem-solving skills they need to be successful in school and in life.

Previous research proves the effectiveness of PC-based gaming used in the classroom ${ }^{34}$. When used with $6^{\text {th }}$ grade students during the regular school year, their Mathematics and Critical Thinking skills scores were very significantly improved ${ }^{35}$. This provides a theoretical framework/ initial feasibility study that we can reference and build on, albeit with robots, in place of PC-games. There are advantages in terms of social interaction, team work and physical activity that PC games do not provide.

Using our cost efficient robots is not just an investment in the technology but more importantly an investment in students' understanding as they aid in the students growing skills sets. They provide greater access to the solutions of more complex mathematical concepts embedded in real-life context. We will use robots to solve math problems (and possibly robotic puzzles and art) not computer games.

Overmars ${ }^{36}$ compared Logo and Lego, opted for the latter, but cited the disadvantages of cost and limited programming. Open source tools and innovations in our robots will overcome both these issues. Hands-on-robotics, however, may be said to present real-world limitations in terms of precise distance and angle measurements. On the contrary, we believe that 'estimation' and the consequent physical and visual realization help capture Mathematics in both its dual roles of a science and a tool.

III.D. Mapping Robot Use in the Math Classroom to Future Skill Demands: As discussed earlier, important standards for college and career readiness are distributed across grades and courses, systems for evaluating college and career readiness should reach as far back in the standards as Grades 6-8. This body of material includes powerfully useful proficiencies such as applying ratio reasoning in real-world and mathematical problems, computing fluently with positive and negative fractions and decimals, and solving real-world and mathematical problems ${ }^{32,37}$. The National Research Council (NRC) ${ }^{37}$ has identified the following as future skill demands: STEM, practical skills that complement concepts, team building and social skills, systems thinking, cognitive adaptability and flexibility, entrepreneurship, communication, and 
abstract thinking and problem solving. Our proposed incorporation of robotics in a math course would prepare in most of these areas. Incorporation of such hands-on team activities in other courses would further strengthen our national fabric for the future.

\section{Engineering Methods:}

More details on robot construction are provided at our website and elsewhere ${ }^{16,29}$.

\section{Results:}

V. A. High School Robotics Course: The purpose of this report is to provide some initial documentation concerning the effects of our robotic art initiative. During the spring of 2012, a semester long elective course on mechatronics was offered at Florida Atlantic University School to 9th grade students. Under the school-wide STEM initiative, the purpose of the course was to enhance students' exposure to, and comfort level with using robotic technology to learn math. Students should benefit from this initiative by both learning mathematical concepts more deeply by connecting math with a real world context and becoming more motivated students to pursue STEM advances and opportunities at FAU. Seventeen ninth grade students in groups of three assembled and programmed robots to draw geometric art on a large (6' x 6') canvas. Students used robotic geometric art to solve math equations and word problems. The use of open source software and hardware helped high school students focus on the experience, rather than dealing with lower level engineering details. They programmed these robots to autonomously plot intermediate complexity mathematical shapes. At the end of the course, groups presented their geometric art in class.

We wanted our course to provide transparency on the software and hardware building blocks, to achieve three things: (1) the students could appreciate better the physics and engineering principles underlying the components. (2) The students could manipulate these components at a high level of abstraction, so they were not burdened with technological and software details. (3) They feel empowered to manipulate the robotic platform to achieve their specific goals.

V. B. The Robots Constructed by Students: Figure 2 shows the two versions of robots that our student teams built. The second version robots (to the right) were built and used by the high school students. These robots had fewer wheels and used a lighter pen fixed in the center of the platform, rather than at the back as with the first version of the robots (to the left) built and used by engineering undergraduate students.

Figure 3 shows an undergraduate student project for creating an intricate pattern. Figure 4 shows three geometric patterns proposed by the high school students. Figure 5 shows a robot autonomously plotting the star and its completed form after the plotting was completed. We have two sites that provide all the presentation videos and links to the student blog sites ${ }^{4,38}$. 

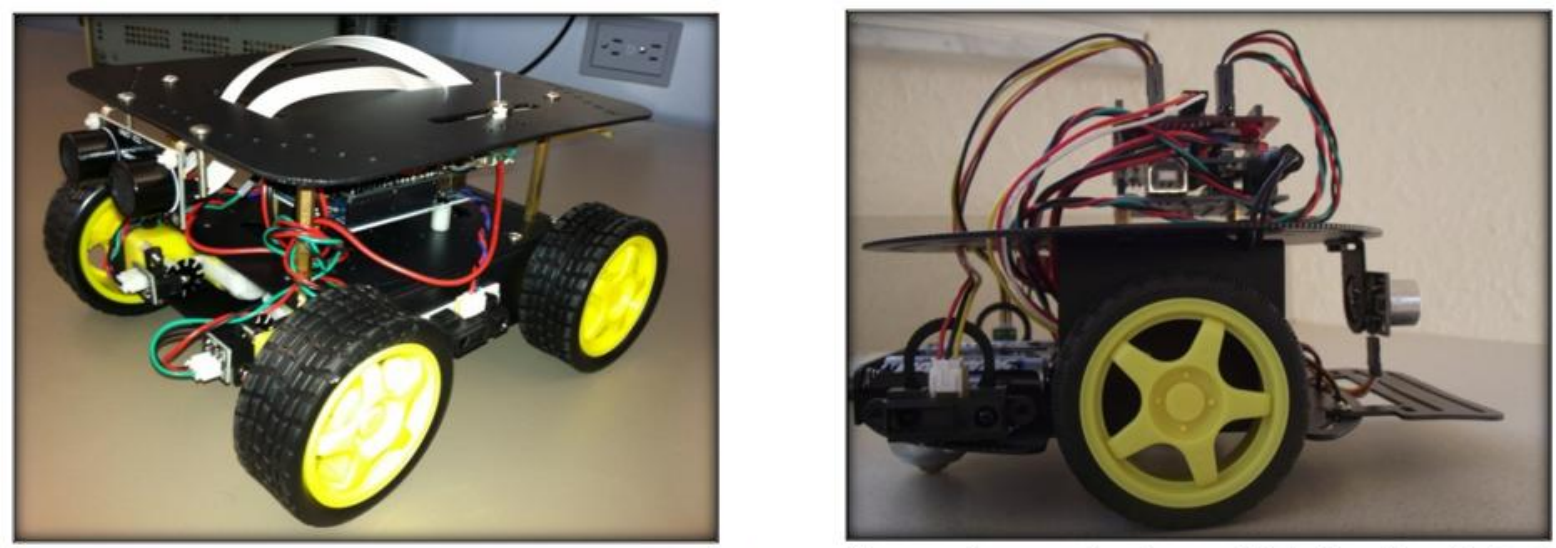

Figure 2: Our first and second robots, built by the undergraduate and high school students, respectively.
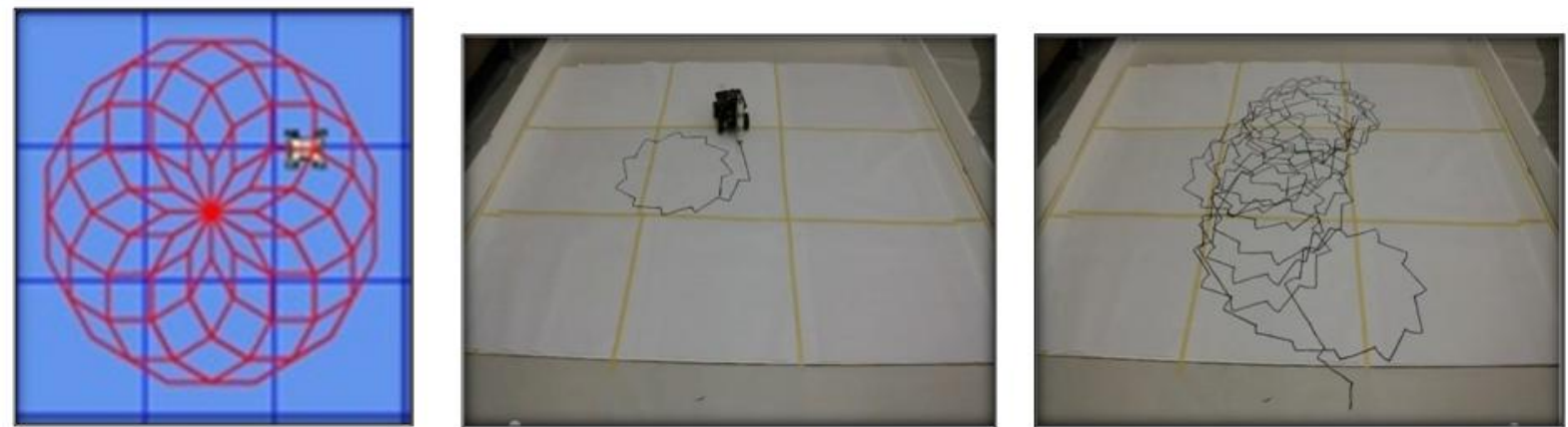

Figure 3: Potential robotic art and its partial implementation in our undergraduate course.
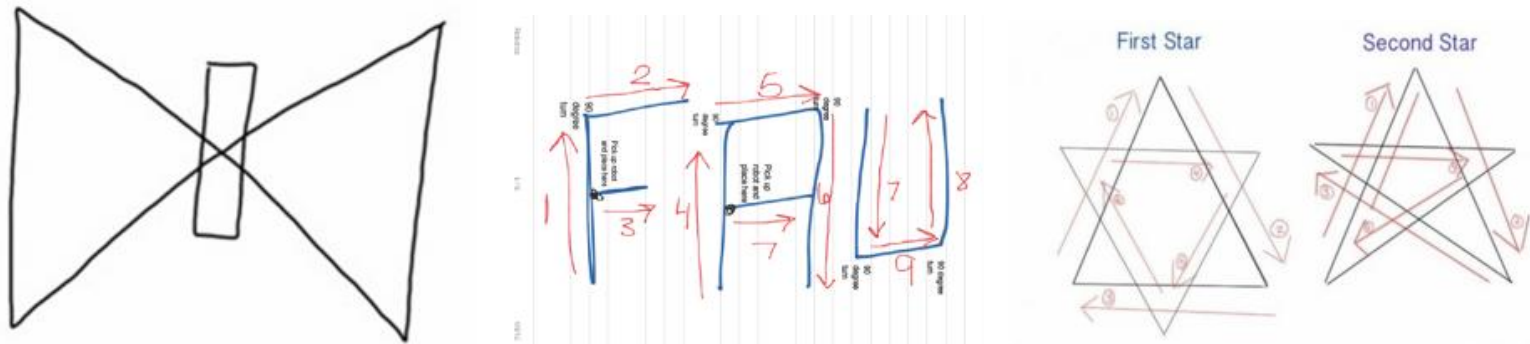

Figure 4: Medium complexity mathematical shapes proposed and implemented in the high school class 

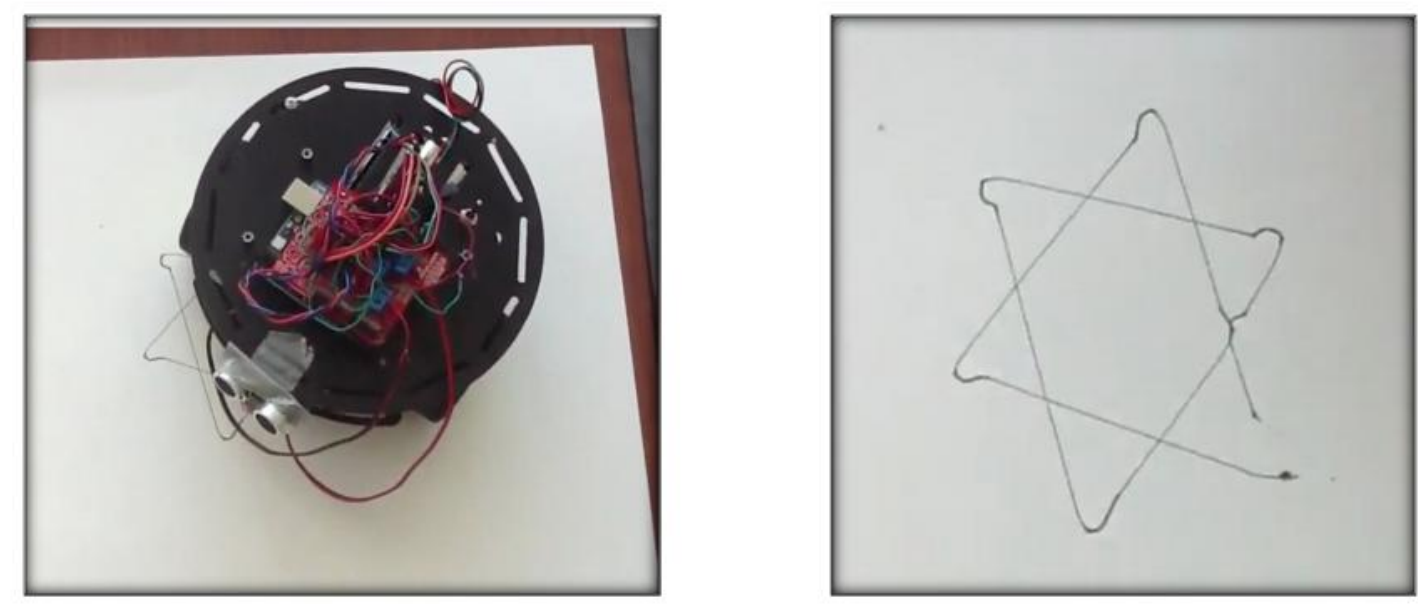

Figure 5: Robotic Plot in progress and completed, for the Star in Figure 3
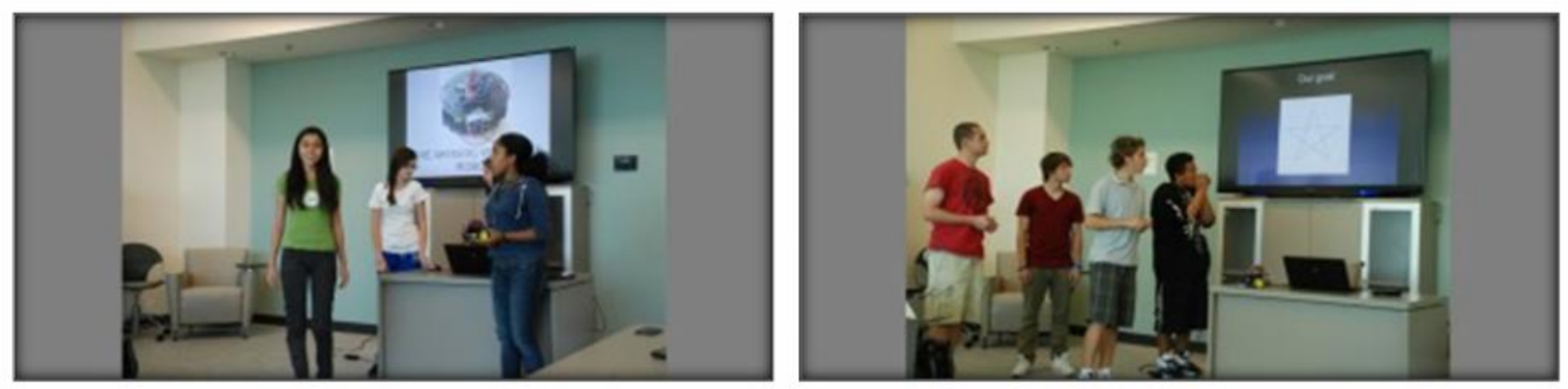

Figure 6: Two of our high school teams

(Please note: The students shown are enrolled at our developmental research school and their parents have signed Photo / Video Release forms).

V. C. Interviews: We interviewed five of the high school students who had signed the institutional review board's consent form for research protocols on human subjects. We interviewed them at the end of the semester in groups of 2 or 3 with the intent to see whether the course made any significant difference in the student's understanding of the underlying Mathematics and Engineering principles. Results from this study, generally encouraging, were published last year ${ }^{18}$.

Having completed Pre-Algebra in 6th grade, algebra in 7th grade, Geometry on line during 8th grade and Algebra 2 in class during 8th grade, one of the interview subjects was in an advanced level Pre-Calculus in 9th grade. He is at least two years ahead in math compared to the regular 9th grade cohorts. The other subject was also at a somewhat accelerated math track and has completed Pre-Algebra in 6th, Algebra 1 in 7th, Geometry in 8th grade and was scheduled in Algebra 2 in 9th grade while in the robotics course. The details of the interviews conducted with these two high school students can be found at our website ${ }^{16}$. A summary is provided below. 
Interview questions:

Students were first told the following:

"Let's start off with a simple problem. Please explain how you would solve it. How would you explain it to someone who is just learning the topic?"

Once these initial instructions were understood, they were given the following problem:

Tamara leaves school and walks 6 blocks east. Then she turns left and walks 8 blocks north. How far did Tamara walk?

Tamara has a pet carrier pigeon that is trained to fly directly from Tamara's house to the school. How far does the pigeon fly?

Now imagine that this is going to be simulated by a robot moving on a map of Tamara's town. The robot is going to trace the path that the carrier pigeon flies. What distance do you expect the robot to travel?

\section{Discussion:}

VI.A. General Comments: These clinical interviews make clear that robotic art could help students realize alternative solutions to solving math problems. Students found a simpler way using visual and spatial knowledge from the canvas to solve the problem that agreed with their answer. They realized that their answer was correct, but that it could be enhanced by demonstrating another method that mapped onto a real world context. In all, these clinical interviews explicitly show how students used the robotic art approach to better conceptualize and solve math problems.

All students interpreted the question as a mathematical problem, which required the Pythagorean Theorem. In each case, the student gave the correct solution, 10 units. The problem did not specify that the pigeon's flight had the same initial and final altitude, and that there were no intervening trees. In of the five interviews, no student mentioned these details. That is, they correctly interpreted the mathematical problem and provided the correct solution. In fact, one student anticipated a question, and gave the correct answer, before the pigeon was mentioned.

The robotic art canvas also seemed to help students to estimate. When discussing the robotic simulation, they all recognized that if the robot odometer read 9.3, there was no serious problem -- that is real world error. However, if the odometer read 17.1, there was a big problem. One student made the interesting comment that perhaps the robot traced the path twice and the odometer was not reset. Students were readily able to understand the difference between conceptual error and real world error. They knew how to solve the mathematical problems, and how to examine the simulations of the robots. They were able to coordinate both types of knowledge into a meaningful pattern.

In regards to future directions, the robotic art canvas can help students with further mathematical insights using patterns that can be mapped directly onto a real world context. There were relevant aspects of the problem that the students did not immediately provide. For example, they calculated the hypotenuse of the $(6,8,10)$ triangle using the Pythagorean Theorem. This was, of course, correct. However, they did not realize that this problem could be also solved using specialized knowledge that the given triangle was a special case of the ratio 3:4:5. With 
prompts, the students did make this connection, and extended their knowledge of the mathematical subject matter and of problem solving.

The students were also able, with prompts, to realize that their work could be used as an instructional tool to a wider range of students. They became aware that they had formed a group where there was much tacit knowledge - shared by the group, but not common to the average high school student. There were ways to communicate this to a broader audience and they became interested in doing so.

We provide below an illustrative example to demonstrate the usefulness of robots in math curriculum.

VI. B. An Example Problem from the Robotics Math Curriculum: Here, we describe and solve the math problem in the conventional way. Section VI.C. explores a robotic approach.

Problem $^{39}$ : Two boats begin their journeys back and forth across a river at the same time, but from opposite sides of the river. The first time that they pass each other they are 700 feet from one of the shores of the river. After they each make one turn, they pass each other once again at a distance of 400 feet from the other shore. How wide is the river? Assume each boat travels at a constant speed and that there is no loss of time in making a turn.

\section{Solution:}

Let $\mathrm{u}$ and $\mathrm{v}$ be the speeds of the two boats, moving from left and right of the shore, respectively. Let $\mathrm{d}$ be the width of the river.

Let them meet at $T_{1}$ the first time. Then $v . T_{1}=d-700$ and $u . T_{1}=700$

Let them meet at $T_{2}$ the second time. Then $v \cdot T_{2}=d+d-400$ and $u \cdot T_{2}=d+400$

Solving gives $\mathrm{u}=0.7 \mathrm{v}$ and $\mathrm{d}=1700$,

\section{Cross-check:}

Assume $\mathrm{v}=100 \mathrm{feet} / \mathrm{second}$ (about $70 \mathrm{mph}$ ), then $\mathrm{u}=70 \mathrm{feet} / \mathrm{second}$.

$\mathrm{T}_{1}=(\mathrm{d}-700) / \mathrm{v}=1000 / 100=10 \mathrm{sec} ; \mathrm{T}_{1}=700 / 70=10 \mathrm{sec}$

$\mathrm{T}_{2}=(2 \mathrm{~d}-400) / \mathrm{v}=3000 / 100=30 \mathrm{sec} ; \mathrm{T} 2=(\mathrm{d}+400) / \mathrm{u}=2100 / 70=30 \mathrm{sec}$

$d_{1}$, the distance from left side, the first time they meet $=u . T_{1}=70.10=700$ feet

$d_{2}$, the distance from right side, the second time they meet $=u . T_{2}-d=70.30-1700=2100$ $1700=400$ feet.

VI. C. The Two Boat Problem Solved Using Robots: We 'solve' here with robotics the problem in VI.B.

Background: One uses robotics to visualize dynamic events and solve problems iteratively using successive approximations. (Successive Approximation is a standard engineering technique that optimizes performance between the two extremes of a totally serial or a totally parallel solution of converting a continuous signal to a digital signal. The serial option is akin to trying out all possible combinations one after the other in Math - that takes time; the parallel option is trying all possible combinations at the same time - and one or more of them will be the right solutions that requires a large number of people). 
Setup: Set up two robots facing each other, across a distance of 12 feet, but able to move towards each other in parallel paths. They are programmed to turn around after covering 12 feet and go in the opposite direction. The plots below assume the origin to be on the left hand side. So, the right robot (red color) starts at 12 feet, while the left robot (blue color) starts at 0 feet. In all the plots below, the $\mathrm{x}$-axis represents time in seconds, while the $\mathrm{y}$-axis represents distance in feet from the left shore, or with respect to the left robot's starting point.

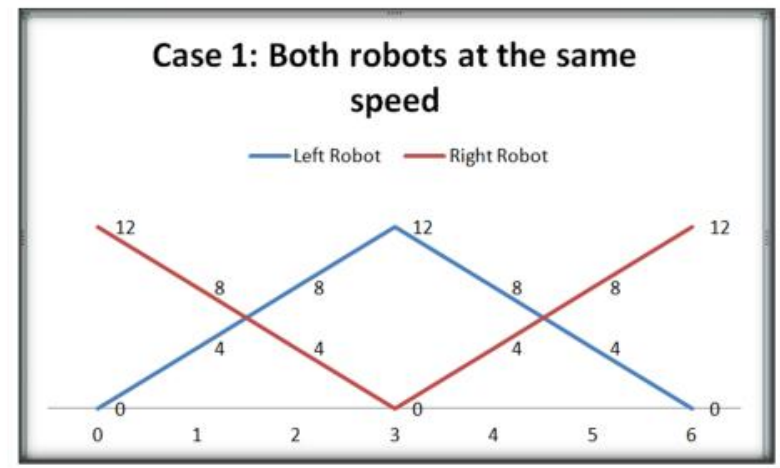

Case 1: let $\mathrm{v}=\mathrm{u}=4$ feet/second. Determine the points of intersection. This will be similar to plotting two lines. They meet at half the distance both ways. But the problem states that the distances to the shore are different the first and second time. Here, $\mathrm{d}_{1}=\mathrm{d}_{2}=6$ feet. But the two distances given in the problem are not the same. So, try a new solution.

Case 2a: Note that one boat may be traveling faster than the other, since they do not meet at the same midpoint both the times. Assume the right robot may be traveling faster, since it seems to be covering more distance both ways. But one may not have this insight (the problem implicitly defines distances from the nearest shore); if so, they can do the Case $2 b$ also (see below). For Case $2 \mathrm{a}$, assume $\mathrm{v}=4 \mathrm{feet} / \mathrm{sec}$, while $\mathrm{u}=2$ feet/sec -- in successive approximations, we divide or multiply by 2 the difference and keep narrowing down to the solution.

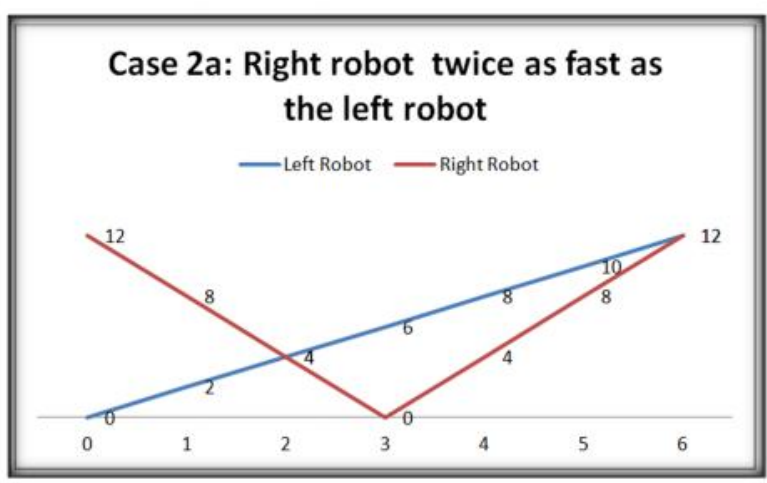

They meet the first time at a distance of 4 feet from the left and the second time at a distance of 12 feet from the left ( 0 feet from the right). But the left robot did not get to turn around. So, we obtain $d_{1}=4$ feet and $d_{2}=0$ feet (recall, from the other shore). However, the trends are in the right direction, but a bit beyond the problem set.

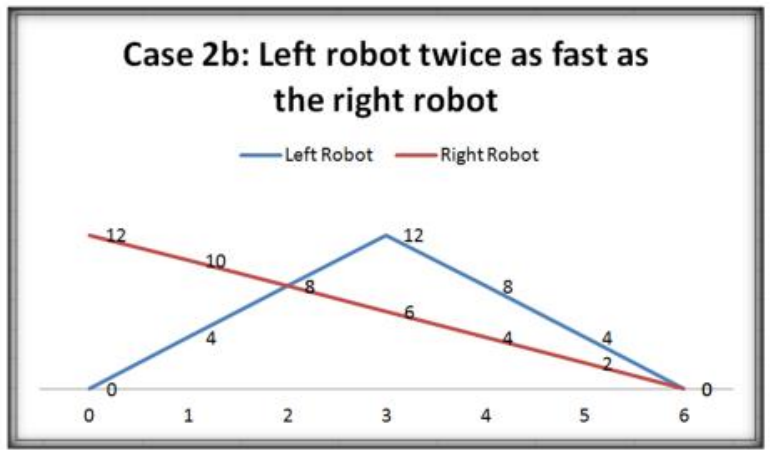

Case $2 \mathrm{~b}$ : Assume $\mathrm{v}=2$ feet $/ \mathrm{sec}$, while $\mathrm{u}=4$ feet/sec -- in successive approximations, we divide or multiply by 2 the difference and keep narrowing down to the solution.

They meet the first time at a distance of 8 feet from the left and the second time at a distance of 
0 feet from the left (or 12 feet from the right). But left robot turned around once, and the right one did not. So, we obtain $\mathrm{d}_{1}=8$ feet and $\mathrm{d}_{2}=12$ feet. The trends are in the opposite direction. So, try Case 2 a now.

Case 3a (similarly, you can do Case $3 b$ etc., until one is clear of the trend, perhaps by plotting the velocity ratio against distance solutions for various cases; not shown here): Twice the speed is too much since they do not meet the second time off the shore. So, let us take the difference and divide by 2 . Thus, choose $u=3$ feet $/ \mathrm{sec}$ and $v=4$ feet $/ \mathrm{sec}$.

They meet the first time at 5.1 feet and the

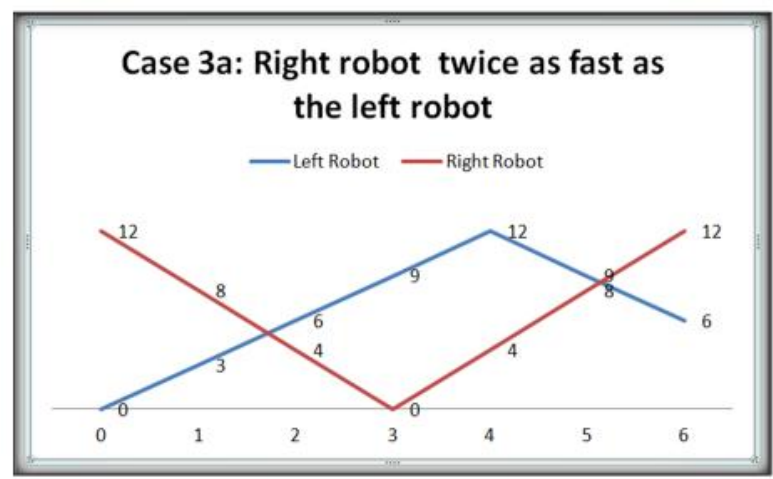
second time at 8.6 feet from the left. Thus $\mathrm{d}_{1}=5.1$ feet and $\mathrm{d}_{2}=3.4$ feet. So, they are now meeting on two sides of the half-way point, but off the shores. Both robots did turn around and did not meet at the middle. So, a solution of $u=0.75 \mathrm{v}$ seems good enough.

VI.D. Advantages of Solving the Problem with Robots: The problem is visually and dynamically solved. Successive approximation was used to identify a trend and come close to a solution. Students can guess and check to make sense of the problem. In doing so, students approached the problem from different angles (scaling, successive approximation and graphing partial results) and solved it in many ways.

The next step in solving the problem could be to identify a step size of 0.5 feet/second. Since we do not know which one is a (marginally) better solution, we go both ways (that is, with left robot velocities of 2.5 and 3.5 feet / second) and evaluate it. This brings up another item: students can stop with the solution from case $3 \mathrm{a}$ and move back to using math to solve the problem. After examining the problem from so many different perspectives, they are now comfortable that the solution is near $\mathrm{u}=0.75 \mathrm{v}$.

None of the above probing can be done on paper or with a graphing calculator since speed is not an independent factor that can be manipulated. Also, even the charts given above do not do justice to the robotic crossings in real-time, since they would have started from the opposite sides. However, software can be written to incorporate all of these ideas into a desktop application. Even then, coupling with robotic movement on the floor would be a good visual reinforcement of the trial-and-error solution approach.

\section{Conclusion:}

As we described in this paper, our team's main objectives are twofold: our on-going work on building low cost robots that use open sources parts that every K-12 school can afford and to help integrating these robots into the mathematics classroom using Understanding by Design (UbD) philosophy ${ }^{1}$.

The interview and the problem solving sequence that we illustrated have shown how students in our robotics program benefited from the use of robots. We looked at a problem that students 
solved using the Pythagorean Theorem and then analyzed the results of the robotic simulation. The students correctly interpreted both the mathematical problem and the real world error that was produced when using the robots. Students were also able to understand the difference between conceptual error and real world error. The students recognized that the robots they built could be used as an instructional tool to a wider range of audience. In all, these clinical interviews explicitly show how students used the robotic art approach to better conceptualize and solve math problems.

We also examined the two-boat problem that we intend to use in our future robotics math classroom. The problem is visually and dynamically solved. Successive approximation is used to identify a trend and come close to a solution. Using robots, students can guess and check to make sense of the problem then look at it from different angles and solve it in many ways. Students need to explore different estimates and evaluate each one until they come close to the solution. After examining the problem from so many different perspectives, they are now comfortable that the result they have gotten with the robots is near to the (mathematically) correct solution. Students can stop with the robotic investigation at any point and solve the problem algebraically. None of the above probing can be done on paper or with a graphing calculator since speed is not a factor.

Learning mathematics with robots helps students visualize challenging real world applications and supports multiple representations of a problem. While students apply their knowledge of math concepts solving real world problems with the help of robots, they develop a lasting handson experience in a social context and a better attitude towards math education. Using our cost efficient robots proved to be more than an investment in the technology. Robots are an investment in students' understanding as they promoted students to try out alternative strategies for solving math problems. Building low cost robots that schools can afford would ensure access, availability and foster mainstream instruction with robots that would help prepare our future generation for 21 st century careers. New ideas will evolve and innovative lessons will be developed that effectively use robots in the math instruction. All will benefit from this innovation as our communities will make progress in educating our next generation in math and engineering principles.

\section{Bibliographical References:}

1. Wiggins, G. and McTighe, J. (2005). Understanding by Design. Expanded $2^{\text {nd }}$ edition. Pearson, Merrill Prentice Hall: Upper Saddle River, NJ.

2. Charles, R.I., Hall, B., Kennedy, A.E., Bragg, S.C., Handlin, W.G., Murphy, S.J., and Wiggins, G. (2012). Algebra 2 - Common Core. Pearson, Boston, MA.

3. Common Core Standards (2012). http://www.corestandards.org/Math . Retrieved in January 2013.

4. FAU Robotics (2012). Florida Atlantic University website for Robotics. http://robotics.fau.edu/

5. Barker, B., Ansorge, J. (2007). Robotics as Means to Increase Achievement Scores in an Informal Learning Environment. Journal of Research on Technology in Education, 39(3), 229-243

6. NSF (2000). National Science Foundation: The Interplay between Mathematics and Robotics. Arlington: National Science Foundation.

7. Rogers, C., \& Portsmore, M. (2004). Bringing engineering to elementary school. Journal of STEM Education, $5(3 \& 4), 17-28$.

8. Papert, S. (1980). Mindstorms. New York. Basic Books. 
9. Brand, B., Collver, M., \& Kasarda, M. (2008). Motivating Students with Robotics. The Science Teacher, 75(4), 44-9.

10. Silk, E., Higashi, R., Shoop, R., \& Schunn, C. (2010). Designing Technology Activities that Teach Mathematics. Technology Teacher, 69 (4), 21-7.

11. MIT Turtle (2012). MIT page on Logo Foundation: A Logo Primer. Retrieved January 6, 2012 from http://el.media.mit.edu/logo-foundation/logo/turtle.html

12. CMU Robot Algebra (2012). Carnegie Mellon University Robotics Academy: Robot Algebra. http://www.education.rec.ri.cmu.edu/content/educators/research/robot_algebra/index.htm

13. CMU LEGO (2012). Carnegie Mellon University Robotics Academy: LEGO Robots. Retrieved January 6 , 2012 from http://www.education.rec.ri.cmu.edu/content/lego/index.htm

14. CMU VEX (2012). Carnegie Mellon University Robotics Academy: The VEX Robotics system. Retrieved January 6, 2012 from http://www.education.rec.ri.cmu.edu/content/vex/index.htm

15. Shankar, R., Ploger, D., Masory, O., and McAfee, F.X. (2011). Robotic Games for STEM Education. ASEE Mid-Atlantic Conference, Philadelphia, PA: Temple University.

16. Additional details on the engineering of robots and the student interviews may be found here: http://csi.fau.edu/wp-content/uploads/2013/03/ASEE-Robotics-Paper-Appendices.pdf

17. Schoenfeld. (1989) Teaching Mathematical Thinking and Problem Solving. In L. B. Resnick \& L. E. Khoper (Eds). Cognitive research in subject matter learning. 1989 Yearbook of the ASCD.

18. Ploger, D., Shankar, R., Nemeth, A., and Hecht, S.A. (2012). Exporting Engineering Technology Practice to Enhance Pre-College Mathematics Learning. In session on Practice Brought into the Engineering Technology Classroom. 2012 ASEE Gulf Southwest Annual Conference. April 4-6, 2012, El Paso, TX.

19. Brazell, J (2009). TEAMS: Prepairing Students for the 21st Century - An Exploration of Emerging Technology, Participatory Culture and Pedagogy. Retrieved April 6, 2013 from http://www.entovation.com/pressroom/TEAMS\%20Preparing\%20Students\%20for\%20the\%2021st\%20Century\%20-\%20Pedagogy.htm

20. NSF (2011). National Science Foundation: Informal Science Education, RFP: NSF 11-546. Retrieved December 2011from http://www.nsf.gov/pubs/2011/nsf11546/nsf11546.htm

21. Polyvore (2012). Concentric Rectangles. Retrieved January 6, 2012 from http://www.polyvore.com/concentric_rectangles/thing?id=6323553.

22. Braunl, T. (2008). Embedded Robotics, Berlin, Germany: Springer.

23. Arduino (2012). Arduino website for open source tools useful to build robots and other embedded systems. Retrieved January 2013, from http://www.arduino.cc/

24. O’Sullivan, D., \& Igoe, T. (2004). Physical Computing: Sensing and Controlling the Physical World with Computers. Boston, MA: Course Technology, a Division of Cengage Learning.

25. Uno (2012) Arduino Board used, retrieved January 2013 from http://www.arduino.cc/en/Main/arduinoBoardUno

26. FAU Android (2012). Florida Atlantic University website for Android Smart Phones. http://android.fau.edu/

27. Shankar, R., and Borras, J. (2007). Radical Productivity Improvement with One Pass to Production (OPP), Ist IEEE Systems Conference, Hawaii, April 2007

28. Shankar, R., Borras, J., McAfee, F., Harris, M., Ploger, D., Masory, O., and Behara, R. Impact of Motorola's Vision on Florida Atlantic University's Engineering Curriculum. Proceedings of the 2013 Conference for Industry and Education Collaboration. February 7-8, 2013. Phoenix, AZ.

29. Shankar, R., Gundel, J.A., Nemeth, A., Ploger, D., and Hecht, S.A., Robotic Art for STEM, 2012 Florida Conference on Recent Advances in Robotics, May 10-11, 2012, Boca Raton, FL.

30. Oracle ThinkQuest (2012). Rene Descartes. Retrieved January 6, 2012 from http://library.thinkquest.org/27694/Rene\%20Descartes.htm

31. O'Connor, J. J., \& Robertson, E. F. (2012). Rene Descartes. MacTutor History of Mathematics. School of Mathematics and Statistics, University of St Andrews, Scotland. Retrieved January 7, 2012 from http://www-gap.dcs.st-and.ac.uk/ history/Biographies/Descartes.html

32. NGA CCSA (2011). National Governors Association Center for Best Practices and the Council of Chief State School Officers: Common Core Standards Initiative. Retrieved April 6, 2013, from http://www.nga.org/cms/render/live/en/sites/NGA/home/nga-center-for-best-practices/center-issues/page-eduissues/col2-content/main-content-list/common-core-state-standards.html

33. Ellington, A. J. (2003). A meta-analysis of the effects of calculators on students' achievement and attitude levels in precollege mathematics classes. Journal for Research in Mathematics Education. 34(5), 433-463. 
34. Harel Caperton, I., Oliver, A., \& Sullivan, S. (2010). A Blueprint for Learning and Leadership in the 21 st Century: Transforming Education Globally Through the Globaloria Learning Network. Retrieved on January 5, 2012, from http://www.worldwideworkshop.org/rep/wwworkshop_annual_report_2010.pdf

35. Minnigerode, L. (2011). Examining Standardized Test Performance in Sixth Grade Globaloria Students. Retrieved January 6, 2012 from http://www.worldwideworkshop.org/pdfs/Quantitative_Data_Report_2011_Grade_6.pdf

36. Overmars, M. (2004). Teaching Computer Science through Game Design. Computer, April, pp. 81-82

37. NRC (2008) National Research Council, Research on Future Skill Demands, Washington, DC: Retrieved January 6, 2012 from http://www.nap.edu/catalog.php?record_id=12066

38. Shankar (2012). Consolidated list of photos, links to blog sites, and presentation videos. http://faculty.eng.fau.edu/shankar/research/robotics/, retrieved in Jan 2013.

39. Sobel, M.A., and Lerner, N., Precalculus Mathematics, 4th edition, Prentice Hall, Englewood Cliffs, NJ, 1991. 